\title{
Association between Parental Behavior and Child's Oral Health among 3-5-year-old Children in Bengaluru City
}

\author{
Bhavna Sabbarwal ${ }^{1}$, Manjunath P Puranik ${ }^{2}, \mathrm{Uma} \mathrm{SR}^{3}$
}

\begin{abstract}
Aim: Parental behavior is known to influence the well-being and disease outcomes in children. The environment which they create for the child can influence oral health behaviors and status. Hence, the present study aimed to determine the association of parental behavior with oral health status among 3-5-year-old children in Bengaluru city.

Materials and methods: A cross-sectional study was conducted among 300 children aged 3-5 years. The child's demographic profile including socioeconomic status, dental history, oral habits, and oral hygiene practices was recorded. A 21-item prevalidated Parenting Style and Dimension Questionnaire (PSDQ) was used to assess parental behavior. WHO oral health pro forma (2013) was used to assess the oral health status of children. Chi-square test, Kruskal-Wallis, and Mann-Whitney $U$-test and binary logistic regression were applied. Statistical significance was considered at $p<0.05$.

Results: The majority of parents were authoritative (64.0\%). The mean age of children was $4.15 \pm 0.74$ years. Sixty-one percent of the children had caries experience. The permissive group had a higher mean dmft $(4.25 \pm 3.43)$ than the authoritarian $(2.1 \pm 1.67)$ and authoritative group $(1.51 \pm 1.94)(p<0.001)$. There was a statistically significant difference between authoritative and permissive $(p<0.001)$ and authoritarian and permissive $(p<0.001)$ groups for $\mathrm{dt}$ and $\mathrm{dmft}$. Parenting style was significantly associated with dental caries and trauma.

Conclusion: There is an association between parental behavior and oral health status among 3-5-year-old children. Hence, a prior appraisal of parental behavior is suggested for better oral health outcomes in children.

Clinical significance: A prior appraisal of parenting style aids the clinician in the more efficient management of children through proper choice of behavior guidance technique.

Keywords: Child, Dental caries, Oral health, Oral hygiene, Parental behavior, Parenting style.

International Journal of Clinical Pediatric Dentistry (2020): 10.5005/jp-journals-10005-1856
\end{abstract}

\section{INTRODUCTION}

Early childhood is an important phase of life when foundations for health-related behavior are laid. The conditions during growing years of life leave a lasting impression on the health of an individual throughout life. ${ }^{1}$ Parents configure their children's behaviors and attitudes through modeling, parenting practices, and interpersonal interactions within the family. ${ }^{2}$ Overall, it can be said that parent's rearing style influences the health-related behaviors of their children. ${ }^{3}$ Some parents are unaware of the health risks their parenting practices place on children. ${ }^{1}$

The role of parenting regarding a child's oral health can be divided into two aspects. At home parents decide on healthy food, brushing teeth, and use of fluoride toothpaste. Second, the behavior of the child during dental treatment might be a reflection of their overall behavior. The dental problems such as dental caries, traumatic injuries, and the associated treatment need might be considered a direct result of these parenting practices. ${ }^{4}$

Baumrind classified three specific parenting styles as authoritative (high warmth, high control), authoritarian (high control, low warmth), and permissive (high warmth, low control). Authoritative parents are both highly demanding and responsive to their children's behaviors (regular oral hygiene) and needs (supporting children). ${ }^{5}$ Research has shown a relationship between authoritative parenting styles and positive behaviors such as healthier food choices, decreased sugary beverage consumption, ${ }^{6,7}$ decreased drug and alcohol use, high self-esteem, and an internal locus of control. ${ }^{6}$ Children with authoritarian parents lack the acceptability of desirable behavior (oral hygiene) which puts them
${ }^{1}$ Department of Public Health Dentistry, Faculty of Dental Sciences, SGT University, Gurugram, Haryana, India

2,3 Department of Public Health Dentistry, Government Dental College and Research Institute, Bengaluru, Karnataka, India

Corresponding Author: Bhavna Sabbarwal, Department of Public Health Dentistry, Faculty of Dental Sciences, SGT University, Gurugram, Haryana, India, Phone: +91 9466857242, e-mail: bhavnasabbarwal@ gmail.com

How to cite this article: Sabbarwal B, Puranik MP, SR Uma. Association between Parental Behavior and Child's Oral Health among 3-5-year-old Children in Bengaluru City. Int J Clin Pediatr Dent 2020;13(6):677-681.

Source of support: Nil

Conflict of interest: None

at risk of developing dental caries. ${ }^{8}$ Permissive parents are often provided unlimited choices to their children and allowed them to play significant roles in decision-making. Hence, oral hygiene measures are less likely to be reinforced. ${ }^{9}$ These psychosocial variables can help identify vulnerability and risk to develop disease among the population in relation to caries development in children. ${ }^{9}$ Hence, dentists should be aware of changing parenting styles as it can save time and patients will be handled more efficiently and effectively. ${ }^{10}$

Studies have investigated the potential relationship between parental behavior, parenting styles in relation to the child's oral health behavior, and dental caries experience. However, there is limited evidence about the association between parental behavior 
and a child's oral health status. Hence, a study was conducted to evaluate the association between parental behavior and oral health status among 3-5-year-old children in Bengaluru city. It was hypothesized that there is no association between a child's oral health status and parental behavior.

\section{Materials and Methods}

A cross-sectional study was conducted from February to May 2017 in Bengaluru city. The study population included 3- to 5-year-old children and their parents. Institutional Ethical Committee and Review Board provided the ethical clearance and permission to conduct the study were taken from the authorities of schools and Anganwadis. The purpose and procedure of the study was explained to the parents and informed consent was obtained for participation.

Training and calibration of the principal investigator were done in the Department of Public Health Dentistry before the start of the study to ensure reliability. The Kappa coefficient value $(\kappa)$ for intraexaminer reliability was 0.80 reflecting a high degree of conformity in observation.

Parenting Style and Dimension Questionnaire (PSDQ) used for assessing parental behavior was checked for its crosscultural validation and reliability. Parenting Style and Dimension Questionnaire is a 21-item prevalidated questionnaire ${ }^{11}$ graded on a five-point Likert scale (1-never, 2-once in a while, 3-half the time, 4-very often, and 5-always). For the authoritative parenting style, there are 9 items with a potential range of scores from 0 to 45 . Both authoritarian and permissive styles include 6 items each with scores ranging from 0 to 35. Back-translation (English to Kannada) method was used for cross-cultural validation of the questionnaire with help of linguistic experts. It was assessed for readability and comprehension during a pilot study. Necessary corrections and modifications were made. Cronbach's alpha (authoritative items = 0.80 , authoritarian items $=0.67$, permissive items $=0.71$ ) was used to determine internal consistency among items.

A pilot study was conducted among 25 children in one of the schools. ${ }^{12}$ Sample size was calculated based on the findings of the pilot study: prevalence of dental caries $=60 \%$, statistical power $=80 \%, Z_{\alpha}=1.96$ at $95 \%$ confidence interval and $10 \%$ margin of error the sample size of 256 was calculated which was rounded off to 300. A list of schools and Anganwadis in Bengaluru city was compiled. ${ }^{13-15}$ Eight schools and Anganwadis were chosen randomly from which 300 study participants were recruited based on their eligibility criteria. Children aged $3-5$ years and their parents were included in the study. While children with any diagnosed medical condition limiting their cognitive development or making oral assessment difficult were excluded.

A structured pro forma was used for data collection. The child's demographic profile including socioeconomic status, ${ }^{16}$ dental history, oral habits, and oral hygiene practices was recorded. Self-administered PSDQ was distributed to the parents. WHO oral health pro forma (2013) for children was used to assess oral health status. ${ }^{17}$ Necessary oral health education and referral as needed was provided for the children after the oral examination.

Statistical Package for Social Sciences (SPSS) version 22 was used for data analysis. Parenting style was determined based on the highest mean score. The difference in proportions and association between the variables was assessed using the Chi-square test. The difference between mean scores was assessed by Kruskal-Wallis and Mann-Whitney $U$-test. Binary logistic regression was applied to check the relationship between sociodemographic variables and parenting style with oral health conditions. Statistical significance was considered at $p<0.05$ (confidence interval of 95\%).

\section{Results}

A total of 3003 - to 5-year-old children with $57.7 \%$ males and 42.3\% females and their parents participated in the study (Table 1). The majority of parents were authoritative (64.0\%) followed by permissive (26\%) and authoritarian (10\%). The mean age of children was $4.15 \pm 0.74$ years. The majority of study participants belonged to the upper-lower middle class.

Oral habits were reported among 102 children: $62.7 \%$ had authoritative, $7.8 \%$ authoritarian, and $29.7 \%$ permissive parents. Regarding dental visits, $84.7 \%$ never visited a dentist whereas $15.3 \%$ had visited a dentist before. In this study, routine checkup was the main reason for dental visits; other reasons were pain and tooth decay. No statistically significant difference was found between parenting style and dental visits among study participants ( $p=0.08$ ). Fillings were found to be more among children with authoritative parents (19.6\%) whereas extraction and oral prophylaxis were almost equally distributed among authoritative and permissive groups. Root canal treatment was reported more in the permissive group. Almost all study participants used toothbrush (99\%) and toothpaste (88.7\%) to clean their teeth.

Mean dmft was found to be $2.28 \pm 2.66$ among study participants which was significantly higher among the permissive group $(4.25 \pm 3.43)$ than authoritarian $(2.1 \pm 1.67)$ and authoritative group $(1.51 \pm 1.94)(p<0.001)$. A statistically significant difference was found with respect to mean $\mathrm{dmft}$ between authoritative and permissive $(p<0.001)$ and authoritarian and permissive groups $(p<0.001)$ (Table 2).

Dental trauma was found among 19 study participants: $36.8 \%$ had authoritative, $15.8 \%$ authoritarian, and $47.4 \%$ permissive parents. The treated dental injury was observed among $15.8 \%$ of study participants all of whom had authoritative parents. Oral mucosal lesions were found among 9 study participants: $66.7 \%$ had authoritarian and $33.3 \%$ permissive parents. Ulceration and candidiasis were found among $77.8 \%$ in $22.2 \%$ of study participants,

Table 1: Distribution of the study participants according to demographic factors and parenting style $(N=300)$

\begin{tabular}{|c|c|c|c|c|c|}
\hline \multicolumn{2}{|c|}{ Demographic factors } & \multirow{2}{*}{$\frac{\text { Authoritative, } n(\%)}{37(12.3)}$} & \multirow{2}{*}{$\frac{\text { Authoritarian, } n(\%)}{7(2.3)}$} & \multirow{2}{*}{$\begin{array}{l}\text { Permissive, } n(\%) \\
18(6.0)\end{array}$} & \multirow{2}{*}{$\frac{\text { Total, N (\%) }}{62(20.7)}$} \\
\hline Age $^{a}$ (years) & 3 & & & & \\
\hline & 4 & $89(29.7)$ & $13(4.3)$ & $28(9.3)$ & $130(43.3)$ \\
\hline & 5 & $66(22.0)$ & $10(3.3)$ & $32(10.7)$ & $108(36.0)$ \\
\hline \multirow[t]{2}{*}{ Gender $^{b}$} & Males & $113(37.7)$ & $19(6.3)$ & $41(13.7)$ & $173(57.7)$ \\
\hline & Females & 79 (26.3) & $11(3.7)$ & $37(12.3)$ & $127(42.3)$ \\
\hline
\end{tabular}

${ }^{\mathrm{a}} p=0.88$

${ }^{\mathrm{b}} p=0.51$ 
Parental Behavior and Oral Health

Table 2: Mean caries experience ( $\mathrm{dmft}$ ) among study participants according to parenting style

\begin{tabular}{lllll}
\hline Caries experience & $\begin{array}{l}\text { Authoritative } \\
(\text { mean } \pm S D)\end{array}$ & $\begin{array}{l}\text { Authoritarian } \\
(\text { mean } \pm S D)\end{array}$ & $\begin{array}{l}\text { Permissive } \\
\text { (mean } \pm S D)\end{array}$ & Total (mean \pm SD) \\
\hline $\mathrm{dt}^{\mathrm{a}}$ & $1.40 \pm 1.90$ & $2.03 \pm 1.59$ & $4.12 \pm 3.28^{\mathrm{b}, \mathrm{c}}$ & $2.17 \pm 2.59$ \\
$\mathrm{mt}$ & $0.02 \pm 0.14$ & $0.07 \pm 0.25$ & $0.04 \pm 0.19$ & $0.03 \pm 0.17$ \\
$\mathrm{ft}$ & $0.08 \pm 0.40$ & 0 & $0.10 \pm 0.38$ & $0.08 \pm 0.38$ \\
$\mathrm{dmft}^{\mathrm{a}}$ & $1.51 \pm 1.94$ & $2.1 \pm 1.67$ & $4.25 \pm 3.43^{\mathrm{b}, \mathrm{c}}$ & $2.28 \pm 2.66$ \\
\hline
\end{tabular}

${ }^{a}$ Statistical significance among the groups $(p<0.001)$

${ }^{\mathrm{b}}$ Statistical significance among authoritative and permissive $(p<0.001)$

'Statistical significance among authoritarian and permissive $(p<0.001)$

Table 3: Association between oral health conditions and parenting styles among study participants

\begin{tabular}{|c|c|c|c|c|c|}
\hline \multicolumn{2}{|c|}{ Oral health and parenting styles, $N=300$} & \multirow{2}{*}{$\begin{array}{l}\text { Authoritative, } n \text { (\%) } \\
88(29.3)\end{array}$} & \multirow{2}{*}{$\begin{array}{l}\text { Authoritarian, } n(\%) \\
27(9.0)\end{array}$} & \multirow{2}{*}{$\begin{array}{l}\text { Permissive, } n(\%) \\
68(22.7)\end{array}$} & \multirow{2}{*}{$\begin{array}{l}\text { Total, N (\%) } \\
183(61.0)\end{array}$} \\
\hline Dental caries experi- & Present & & & & \\
\hline & Absent & $104(34.7)$ & $3(1.0)$ & $10(3.3)$ & $117(39.0)$ \\
\hline \multirow[t]{2}{*}{ Dental traumab } & Present & $7(2.3)$ & $3(1.0)$ & $9(3.0)$ & $19(6.3)$ \\
\hline & Absent & $185(61.7)$ & $27(9.0)$ & $69(23.0)$ & $281(93.7)$ \\
\hline \multirow[t]{2}{*}{ Oral mucosal lesions ${ }^{c}$} & Present & $6(2.0)$ & $0(0)$ & $3(1.0)$ & $9(3.0)$ \\
\hline & Absent & $186(62.0)$ & $30(10.0)$ & $75(25.0)$ & $291(97.0)$ \\
\hline
\end{tabular}

Table 4: Distribution of study participants according to urgent needs of a different intervention and parenting style

\begin{tabular}{lcccc}
\hline Intervention urgency & Authoritative, $n(\%)$ & Authoritarian, $n(\%)$ & Permissive, $n(\%)$ & Total, $N(\%)$ \\
\hline No treatment & $68(22.7)$ & $3(1.0)$ & $6(2.0)$ & $77(25.7)$ \\
Preventive/routine treatment & $33(11.0)$ & $7(2.3)$ & $8(2.7)$ & $48(16.0)$ \\
Prompt treatment & $81(27.0)$ & $16(5.3)$ & $48(16.0)$ & $145(48.3)$ \\
Immediate treatment & $10(3.3)$ & $4(1.3)$ & $16(5.3)$ & $30(10.0)$ \\
Referred for comprehensive & $0(0)$ & $0(0)$ & $0(0)$ & $0(0)$ \\
evaluation & & $30(10.0)$ & $78(26.0)$ & $300(100.0)$ \\
Total & $192(64.0)$ & & & \\
\hline
\end{tabular}

respectively. A statistically significant association of parenting styles to caries experience $(p<0.001)$ and dental trauma ( $p=$ 0.04 ) was found. Association between parenting styles and oral mucosal lesions was not found to be statistically significant ( $p=$ 0.57) (Table 3).

Very mild and mild enamel fluorosis was found among 11.7 and $0.7 \%$ of study participants, respectively. Regarding very mild fluorosis: $4.3 \%$ had authoritative, $2.0 \%$ authoritarian, and $5.4 \%$ permissive parents. Mild fluorosis was seen in $0.3 \%$ of study participants each among authoritative and permissive groups.

Preventive/routine treatment was required for $16.0 \%$ of study participants: $11.0 \%$ had authoritative, $2.3 \%$ authoritarian, and $2.7 \%$ permissive parents. Prompt treatment was needed for $48.3 \%$ of study participants where $27.0 \%$ had authoritative, $5.3 \%$ had authoritarian, and $16.0 \%$ had permissive parents (Table 4).

Study participants aged $4(O R=1.16)$ or 5 years $(O R=1.72)$ were found to be having higher chances of dental caries compared to those aged 3 years although the association was not significant ( $p$ $\geq 0.05$ ). Females had higher odds of having dental caries compared to males (OR $=1.46$ ) but the association was not found to be significant $(p \geq 0.05)$. Study participants with authoritarian $[\mathrm{OR}=$ $10.64(p<0.001)]$ and permissive parents $[\mathrm{OR}=8.04(p<0.001)]$ were significantly more likely to have dental caries than those with authoritative parents. Study participants in the upper-middle $(\mathrm{OR}=$ 1.74), lower-middle ( $O R=2.29)$, and upper-lower class $(O R=1.80)$ were more likely to have dental caries than those in the upper socioeconomic class but the association was not significant ( $p \geq$ 0.05).

Study participants aged $4(\mathrm{OR}=0.55)$ and 5 years $(\mathrm{OR}=0.91)$ were less likely to have dental trauma than those aged 3 years but the association was not found to be significant $(p \geq 0.05)$. Females were more likely to have dental trauma than males $(O R=1.96)$, although the association was not significant ( $p \geq 0.05)$. Study participants with authoritarian parents were more likely to have dental trauma than those with authoritative parents $(O R=2.93)$, although the association was not significant $(p \geq 0.05)$. Those with permissive parents were significantly more likely to have dental trauma compared to those with authoritative parents [OR $=3.45$ $(p=0.02)]$. Study participants with authoritarian parents were more likely to have dental trauma than those with authoritative parents $(\mathrm{OR}=2.93)$, although the association was not significant $(p \geq 0.05)$. Those with permissive parents were significantly more likely to have dental trauma compared to those with authoritative parents $[\mathrm{OR}=3.45(p=0.02)]$. 


\section{Discussion}

Parental behavior affects parenting style which may influence a child's growth and development. Children adopt behavior from their parents when young especially when parents are responsive to child's needs and feelings as well as make them understand the consequences of good or bad behavior. ${ }^{18}$ Parenting has an impact on the development of oral self-care habits in children.

The majority of parents in the present study were authoritative similar to earlier studies. ${ }^{3,8-10,19,20}$ As found in previous studies no statistically significant difference with respect to parenting styles and age group was observed in the current study. ${ }^{21,22}$ In this study, the proportion of males (57.7\%) was higher than females $(42.3 \%)$ which is in accordance with some studies ${ }^{3,8,10,20,23,24}$ while in others females were higher., $9,25,26$

Economic hardship results in increased levels of anxiety, irritability, and depression which leads to inconsistent parental behavior whereas affluent parents may have more supportive, sensitive, and involved parenting behavior toward their children. In the current study, the level of education/occupation/income varies with the parenting styles with a higher proportion of authoritative parents at a higher level of social class.

Authoritative parents brought their children to the dentist ${ }^{8}$ whereas dental treatment deferred in case of other parenting styles because of perception that their children would suffer from the effects of procedural measures and even allowed them to withdraw from the treatment. ${ }^{4}$

Laxness (permissive characteristic) has been related to dental anxiety/fear in the previous studies. ${ }^{27-29}$ In this study, less than onefifth of the study participants reported visiting a dentist majority being authoritative parents.

Parental behavior may have an influence on the development of oral habits at an early stage. These habits interfere with the normal growth and the function of the jaws and orofacial musculature, respectively. ${ }^{24}$ In this study, lip/nail/pencil biting or tongue thrusting habit were the commonly reported habits.

In this study, routine checkup was the main reason for dental visits; other reasons were pain and tooth decay which is in line with a previous study. ${ }^{19}$ Treatment varied with the type of parenting: fillings (authoritative parents) and root canal treatment (permissive group). In previous studies, extraction, ${ }^{27}$ filling, ${ }^{19,27}$ and oral prophylaxis ${ }^{19}$ were the treatment received regardless of parenting styles.

Children with the authoritative and authoritarian type of parents are expected to perform oral hygiene more regularly because of strict rules which a characteristic of this type of parenting. If strict rules are created regarding oral hygiene measures then children would abide by these rules. ${ }^{8}$ Studies have shown that authoritative parents help to establish desirable oral health behavior like regular toothbrushing. ${ }^{2,7}$ However, in this study, almost all study participants had optimal oral hygiene practices irrespective of parenting style which is almost similar to previous studies (100\%). ${ }^{2,19,26}$

Caries experience may vary according to the parenting style. Children in permissive households may be able to eat and drink cariogenic foods unabatedly and can also choose whether or not to brush their teeth without expectation of discipline/ enforcement. While among children with authoritarian parents, the oral hygiene and diet measures are not reinforced due to the low parental responsiveness. ${ }^{8}$ Dental caries was present among $61.0 \%$ of study participants which is in line with previous studies
(42.6-68.5\%). ${ }^{8,9,26,27,30}$ Among those having dental caries majority belonged to authoritarian and permissive parents. In a similar study, caries was found in $91.0 \%$ of children among authoritarian and $97.0 \%$ of children among permissive parents. ${ }^{8}$

Mean dmft was less than a study (6.8). ${ }^{31}$ Mean caries and caries experience ( $\mathrm{dt}$ and $\mathrm{dmft}$ ) were significantly higher among children with permissive parents. The missing component was higher among the authoritarian group. Mean $\mathrm{ft}$ was higher in the permissive group, whereas there was no filled component in the authoritarian group. Dental caries was significantly associated with parenting style in this study which is in accordance with previous studies ${ }^{1,8}$ whereas one study found no association. ${ }^{32}$

Study participants aged 4 or 5 years, females had higher odds of having dental caries compared to their counterparts. Regarding social class, study participants in upper-lower middle and lower class had more chances of having dental caries compared to those in the upper class. In one study, middle class had significantly higher dental caries with reference to the upper class. ${ }^{19}$ However, age, gender, and social class were not significantly associated with dental caries in the present study. Study participants with authoritarian (OR $=10.64)$ and permissive parents $(O R=8.04)$ had significantly higher chances to have dental caries compared to authoritative parents.

Young children are more prone to traumatic dental injuries due to their poor stability, reflexes, and indefinite movements. Parents and the home environment seem to have an impact on traumatic dental injuries in young children. ${ }^{33}$ Proportion of dental injuries were found more among children with permissive parents while treated injuries were observed only in authoritative parents. A significant association was observed between parental style and dental trauma. Study participants aged 4 or 5 years and males were less likely to have dental trauma compared to corresponding age and gender. Regarding social class, dental trauma was more likely to be found among study participants in upper-lower middle and lower class compared to those in the upper class. In this study, age, gender, and social class were not found to be significantly associated with dental trauma. Whereas the association between low socioeconomic status and dental trauma has been reported in previous literature. ${ }^{33}$ Study participants with permissive $(\mathrm{OR}=$ 3.45) and authoritarian parents $(\mathrm{OR}=2.93)$ were more likely to have dental trauma with reference to authoritative parents, although the association was statistically significant for the permissive group only.

The present study has some limitations. The bias inherent in questionnaire studies may have occurred in this study. The majority reported to be exhibiting authoritative parenting (social desirability bias); however, anonymity was ensured to obtain true characteristics of the parents. Causal effect relationships between parenting styles and oral health status of children could not be assessed by crosssectional study design, although significant associations may serve as indicators. Unequal distribution of the study sample among the parenting types may limit understanding of the association between parental behavior and oral health status of children. However, random sampling technique may have ensured sampling of the existing pattern of parenting in this study.

As unhealthy behaviors are difficult to change during the adult years, it is important to intervene before problematic behaviors become established. A prior appraisal of parenting style in addition to a child's behavior is required to aid the clinician in the more efficient management of children through proper choice of behavior guidance technique. Application of authoritative 
parenting practice related to oral health improves expected behavior such as optimal oral hygiene measures and dietary practices on part of a child. Consideration of parenting styles in oral health preventive programs is recommended. Longitudinal studies are recommended for a better understanding of the association between parental behavior, child behavior, and oral health status of the child.

\section{Conclusion}

Most of the parents were authoritatively followed by permissive and authoritarian. Majority of children had dental caries experience which was found to be higher in children with permissive and authoritarian parents. Parental behavior had a significant association with dental caries and trauma. Children with authoritative parents had better oral health status compared to those with authoritarian and permissive parents in this study suggestive of an association between parental behavior and oral health.

\section{Clinical Significance}

As concluded the parenting style affects the oral health and hygiene of children prior appraisal of parenting style will in more efficient management with proper behavior guidance technique.

\section{References}

1. Hooley $M$, Skouteris $H$, Boganin C, et al. Parental influence and the development of dental caries in children aged 0-6 years: a systematic review of the literature. J Dent 2012;40(11):873-885. DOI: 10.1016/j. jdent.2012.07.013.

2. de Jong-Lenters M, Duijster $D$, Bruist MA, et al. The relationship between parenting, family interaction and childhood dental caries: a case-control study. Soc Sci Med 2014;116:49-55. DOI: 10.1016/j. socscimed.2014.06.031.

3. Park H, Walton-Moss B. Parenting style, parenting stress and children's health related behaviours. Dev Behav Pediatr 2012;33(6):495-503. DOI: 10.1097/DBP.0b013e318258bdb8.

4. Law CS. The impact of changing parenting styles on the advancement of pediatric oral health. J Calif Dent Assoc 2007;35(2):192-197.

5. Brukiene V, Aleksejuniene J. Is the authoritative parenting model effective in changing oral hygiene behavior in adolescents? Health Educ Res 2012;27(6):1081-1090. DOI: 10.1093/her/cys074.

6. Aleksejuniene J, Brukiene V. Parenting style, locus of control and oral hygiene in adolescents. Medicina (Kaunas) 2012;48(2):102-108. DOI: 10.3390/medicina48020009.

7. Lopez NV, Ayala GX, Corder K, et al. Parent support and parentmediated behaviors are associated with children's sugary beverage consumption. J Acad Nutr Diet 2012;112(4):541-547. DOI: 10.1016/j. jand.2011.11.013.

8. Howenstein J, Kumar A, Casamassimo PS, et al. Correlating parenting styles with child behaviour and caries. Pediatr Dent 2015;37(1):59-64.

9. Seran N, Demopoulos C, Mobley C, et al. Parenting style and oral health status. Open J Pediatr 2013;3(03):188-194. DOI: 10.4236/ ojped.2013.33033.

10. Aminabadi NA, Farahani RM. Correlation of parenting style and pediatric behaviour guidance strategies in the dental setting: preliminary findings. Acta Odontol Scand 2008;66(2):99-104. DOI: 10.1080/00016350802001322.

11. Biletchi J, Macintosh J, Mclsaac K, A provincial assessment of parenting styles in Ontario- Public Health Ontario. Available at: https://www. Publichealthontario.

12. List of playschools in Bangalore. Available at: https://www. indianplayschools.com/Bangalore-preschools. (Last accessed on: 10/10 2016).
13. List of Schools Names \& Addresses in Bangalore, India. Available at: www.indiacom.com/yellow-pages/schools/bangalore. (Last accessed on: 10/10/2016).

14. List of Government \& Municipal High Schools Names in Bangalore, India. Available at: www.indiacom.com/yellow-pages/governmentmuncipal-schools/Bangalore. (Last accessed on: 10/10/2016).

15. Details for District wise location of Anganwadi Centres in Karnataka. Department of women and child development. Government of Karnataka. Available at: dwcdkar.gov.in > Acts and Documents > Downloads. (Last accessed on: 10/10/2016).

16. Singh T, Sharma S, Nagesh S. Socio-economic status scales updated for 2017. Int J Res Med Sci 2017;5(7):3264-3267. DOI: 10.18203/23206012.ijrms20173029.

17. World Health Organization. Oral Health Surveys-Basic Methods. 5th ed., Geneva: WHO; 2013.

18. Darling N, Steinberg L. Parenting style as context: an integrative model. Psychol Bull 1993;113(3):487-496. DOI: 10.1037/00332909.113.3.487.

19. Dabawala S, Suprabha BS, Shenoy R, et al. Parenting style and oral health practices in early childhood caries: a case-control study. Int J Paediatr Dent 2017;27(2):135-144. DOI: 10.1111/ipd.12235.

20. Aminabadi NA, Deljavan A, Zahrajamali, et al. The influence of parenting style and child temperament on child-parent-dentist interactions. Pediatr Dent 2015;37(4):342-346.

21. ten Berge M, Veerkamp JS, Hoogstraten J, et al. Childhood dental fear in relation to parental child-rearing attitudes. Psychol Rep 2003;92(1):43-50. DOI: 10.2466/pr0.2003.92.1.43.

22. Krikken JB, van Wijk AJ, ten Cate JM, et al. Child dental anxiety, parental rearing style and referral status of children. Community Dent Health 2012;29(4):289-292.

23. Freudenthal JJ, Bowen DM. Motivational interviewing to decrease parental risk-related behaviour for early childhood caries. J Dent Hyg 2010;84(1):29-34.

24. Josell SD. Habits affecting dental and maxillofacial growth and development. Dent Clin North Am 1995;39(4):851-860.

25. Aminabadi NA, Pourkazemi M, Babapour J, et al. The impact of maternal emotional intelligence and parenting style on child anxiety and behaviour in the dental setting. Med Oral Patol Oral Cir Bucal 2012;17(6):1089-1095. DOI: 10.4317/medoral.17839.

26. Peltzer K, Mongkolchati A, Satchaiyan G, et al. Sociobehavioural factors associated with caries increment: a longitudinal study from 24 to 36 months old children in Thailand. Int J Environ Res Public Health 2014;11(10):10838-10850. DOI: 10.3390/ijerph111010838.

27. Krikken JB, Vanwijk AJ, Tencate JM, et al. Child dental anxiety, parental rearing style and dental history reported by parents. Eur J Paediatr Dent 2013;14(4):258-262.

28. Venham LL, Murray P, Gaulin-Kremer E. Child-rearing variables affecting the preschool child's response to dental stress. J Dent Res 1979;58(11):2042-2045. DOI: 10.1177/00220345790580110101.

29. Krikken JB, Veerkamp JS. Child rearing styles, dental anxiety and disruptive behaviour: an exploratory study. Eur Arch Paediatr Dent 2008;9(Suppl 1):23-28. DOI: 10.1007/BF03262652.

30. Lencova E, Pikhart H, Broukal Z, et al. Relationship between parental locus of control and caries experience in preschool children - crosssectional survey. BMC Public Health 2008;8(1):208. DOI: 10.1186/14712458-8-208.

31. Duijster $D$, de Jong-Lenters $M$, de Ruiter $C$, et al. Parental and familyrelated influences on dental caries in children of Dutch, Moroccan and Turkish origin. Community Dent Oral Epidemiol 2015;43(2):152-162. DOI: 10.1111/cdoe.12134.

32. Seow WK, Clifford H, Battistutta D, et al. Case-control study of early childhood caries in Australia. Caries Res 2009;43(1):25-35. DOI: 10.1159/000189704.

33. Chalissery VP, Marwah N, Jafer M, et al. Prevalence of anterior dental trauma and its associated factors among children aged 3-5 years in Jaipur city, India - a cross sectional study. J Int Soc Prev Community Dent 2016;6(Suppl 1):S35-S40. DOI: 10.4103/2231-0762.181165. 